\title{
Editorial
}

\section{Heparin for coronary angioplasty: high dose, low dose, or no dose?}

We have celebrated the 20th anniversary of the first percutaneous transluminal coronary angioplasty (PTCA) by Grüntzig. We have seen many efforts to render PTCA simpler and safer. While technological progresses have allowed us to approach ever more complex coronary lesions, there has been a tremendous effort to optimise medical treatment as an adjunct to mechanical dilatation of coronary lesions. A variety of anticoagulant and antiplatelet agents have been used from the beginning to minimise the risk of abrupt coronary occlusion during and after PTCA.

Various studies have shown that heparin and aspirin significantly reduce the incidence of acute ischaemic complications of PTCA. Other antiplatelet and antithrombotic agents have been used for the same purpose. ${ }^{1}$ Some of the initial drugs were of little help or even harmful and they were abandoned. For example, for intracoronary stents periprocedural anticoagulation was initially considered essential, until objective data favoured more simple drug regimens. $^{2}$

The exact dose of heparin needed during coronary interventions and the length of postprocedural heparin infusion is not yet established. Pretreatment with heparin in patients with intracoronary thrombus and unstable angina has reduced the incidence of acute ischaemic complications. ${ }^{3}$ In many centres, an initial bolus of 10 000-15000 units of heparin and further boluses to achieve activated clotting times (ACT) of over 300 seconds are routine. Yet, there is no evidence of a solid correlation between a given ACT and the risk of acute coronary occlusion. The recommended threshold of 300 seconds is an arbitrary cut off largely based on analyses performed in patients during cardiopulmonary bypass. Narins et al recently found an inverse correlation between the level of anticoagulation (measured by ACT) and the occurrence of acute ischaemic periprocedural complications in patients undergoing PTCA. ${ }^{4}$ In contrast, several randomised studies have suggested efficacy and safety of low dose heparin during elective PTCA procedures, independent of ACT. ${ }^{56}$ Higher doses of anticoagulants increase the risk of bleeding, which has to be considered when assessing the net advantage of intensive anticoagulation over low dose heparin in the setting of routine coronary interventions.

Abrupt vessel closure during PTCA may be an infrequent event; however, it carries a considerable risk for the patient. ${ }^{7}$ The mechanisms of acute vessel closure are multiple and include plaque disruption, intimal dissection, coronary spasm, subintimal haemorrhage, and thrombus formation. Plaque rupture (spontaneous or by PTCA) exposes the thrombogenic subendothelial layers to platelets and coagulation proteins. Activation of platelets and the coagulation cascade are the fundamental mechanisms of arterial thrombosis, and are closely linked. Thrombin generated by blood coagulation is a potent platelet activator, and activated platelets potentiate the process of coagulation. Depending on flow conditions, there are differences between arterial and venous thrombi in their relative composition of fibrin and platelets. ${ }^{8}$ Arterial thrombi form even under high flow conditions and are composed mainly of platelet aggregates bound together by thin fibrin strands (white thrombus). Venous thrombi are rich in fibrin and red blood cells and contain relatively few platelets (red thrombus). The important role of platelet activation in thrombus formation during PTCA was confirmed by several animal models and human studies. ${ }^{9}{ }^{10}$

In the past few years, more effective platelet blockade has gained interest in the quest to decrease thrombotic complications during and after PTCA. The development and clinical use of specific glycoprotein (GP) IIb/IIIa antagonists in high risk PTCA procedures resulted in a significant reduction of acute ischaemic complications. Recent randomised trials with GP IIb/IIIa antagonists have shown best efficacy and safety in conjunction with weight adjusted low dose heparin (about 5000 units) in terms of both ischaemic and bleeding complications. ${ }^{11}$ In the EPIC trial, high risk patients having PTCA, including many with unstable angina, were randomly assigned to receive a GP $\mathrm{IIb} / \mathrm{III}$ antagonist (abciximab) or placebo in addition to full dose heparin. The incidence of major cardiac complications was significantly higher in the placebo group but full heparinisation proved a problem in conjunction with abciximab. ${ }^{12}$ This supports starting routine coronary interventions with 5000 units of heparin, not to preclude the use of these agents if indicated. The alternative, to neutralise part of the heparin before adding a GP IIb/IIIa antagonist, is less appealing.

Koch and colleages ${ }^{13}$ corroborated the hypothesis that low dose heparin with "suboptimal" anticoagulation during routine PTCA procedures has no adverse effect on the outcome of patients. ${ }^{14}$ They analysed a large number of patients representing over $75 \%$ of the population of a busy catheterisation laboratory. In almost $90 \%$ of this population, a 5000 unit bolus of heparin in addition to aspirin was the sole anticoagulant regimen. Whether the use of ioxaglate, which has been shown to have some anticoagulant effect, ${ }^{15}$ further reduced thrombotic complications is unclear. The ACTs in 50 patients after the administration of 5000 units of heparin were largely below the safety threshold reported in the literature. Nevertheless, the ischaemic complications remained in an acceptable range supporting the evidence that a low ACT does not predispose to abrupt closure. Bailout stenting was used in only $1.3 \%$ of the patients, which is far below current practice. It is possible that with more liberal use of intracoronary stents to optimise the angiographic results of PTCA, acute and subacute closures can be reduced further even under low dose heparinisation. ${ }^{56}$

In Koch et al's study, 123 patients (9\%) were given prolonged postintervention heparin; however, 45 of them still had acute ischaemic complications. Whether prolonged postprocedure heparin prevents or just postpones acute closure has been the issue of iterative debate. Recently published randomised trials have failed to show any significant beneficial effect of prolonged heparin after uncomplicated coronary interventions. ${ }^{16}$ The incidence of puncture site complications in patients with prolonged heparin infusion, however, was three times that of patients with a single bolus of heparin. 
Low dose single bolus heparin makes particular sense if early sheath removal is performed. This also means enhanced patient comfort, short hospital stay, and reduced cost. Low dose heparin for routine PTCA can be considered a safe and established policy facilitating the use of modern potent antiplatelet agents in case of need. To think the unthinkable, we might live to see the day where heparin is completely abandoned.

1 Neuhaus KL, Zeymer U. Prevention and management of thrombotic complications during coronary interventions. Combination therapy with antithrombins, antiplatelets, and/or thrombolytics: risks and benefits. Eur Heart f 1995;16:63-7.

2 Schömig A, Neumann FJ, Kastrati A, et al. A randomized comparison of antiplatelet and anticoagulant therapy after the placement of coronaryartery stents. N Engl F Med 1996;334:1084-9.

3 Laskey M, Deutsch E, Hirshfeld J, et al. Influence of heparin therapy on percutaneous transluminal coronary angioplasty outcome in patients with cutaneous transluminal coronary angioplasty outcome in

4 Narins CR, Hillegass WB Jr, Nelson CL, et al. Relation between activated clotting time during angioplasty and abrupt closure. Circulation 1996;93: clotting tim $667-71$.

5 Garachemani A, Fleisch M, Vainer J, et al. Low dose heparin for routine coronary angioplasty and stenting: a randomized double blind study [abstract]. Circulation 1996;94:1149.

6 Boccara A, Benamer H, Juliard JM, et al. A randomized trial of a fixed high dose vs a weight adjusted low dose of intravenous heparin during coronary angioplasty. Eur Heart f 1997;18:631-5.

7 De Feyter PJ, Van den Brand M, Jaarman G, et al. Acute coronary artery occlusion during and after percutaneous transluminal coronary angi- oplasty. Frequency, prediction, clinical course, management, and followup. Circulation 1991;83:927-36.

8 Badimon L, Badimon J, Fuster V. Pathogenesis of thrombosis. In: Fuster V, Verstraete M, eds. Thrombosis in cardiovascular disorders. Philadelphia: Saunders Co, 1992:1-16.

9 Steele PM, Chesebro JH, Stanson AW, et al. Balloon angioplasty. Natural history of the pathophysiological response to injury in a pig model. Circ Res 1985;57:105-12.

10 Gasperetti CM, Gonias SL, Gimple LW, et al. Platelet activation during coronary angioplasty in humans. Circulation 1993;88:2728-34.

11 The EPILOG Investigators. Platelet glycoprotein IIb/IIIa receptor blockade and low-dose heparin during percutaneous coronary revascularization. $N$ Engl f Med 1997;336:1689-703

12 Topol EJ, Califf RM, Weisman HF, et al. Randomised trial of coronary intervention with antibody against platelet IIb/IIIa integrin for reduction of clinical restenosis: results at six months. Lancet 1994;343:881-6.

13 Koch K, Piek J, de Winter R, et al. Safety of low dose heparin in elective coronary angioplasty. Heart 1997;77:517-22.

14 Frierson JH, Dimas AP, Simpfendorfer CC, et al. Is aggressive heparinization necessary for elective PTCA? Cathet Cardiovasc Diagn 1993;28:279-82.

15 Corot C, Chronos N, Sabattier V. In vitro comparison of the effects of contrast media on coagulation and platelet activation. Blood Coagul Fibrinolysis 1996;7:602-8

16 Friedman HZ, Cragg DR, Glazier SM, et al. Randomized prospective evaluation of prolonged versus abbreviated intravenous heparin therapy after coronary angioplasty. F Am Coll Cardiol 1994;24:1214-19.

A GARACHEMANI

B MEIER

Department of Cardiology,

University Hospital,

3010 Bern-Switzerland

\section{STAMPS IN CARDIOLOGY}

\section{Digitalis and strophanthus - cardiac glycosides}

Digitalis lanata is shown on the 35 dinar Yugoslavian stamp from a set of nine issued in 1957, which includes the deadly nightshade and the meadow saffron. In 1966 Bulgaria also issued a set of flower stamps with the 2 stotinki value showing Digitalis purpurea. Bulgaria had previously depicted the foxglove in a set of 14 on medicinal plants in 1953. The Congo Republic issued eight stamps to commemorate the centenary of the Red Cross organisation in 1963. Strophanthus sarmentosus appeared on three of the values with the design showing a fine engraving of the plant with the emblem of the Red Cross. Also issued was a miniature sheet of three stamps showing Strophanthus and Cinchona ledgeriana.

Plants are the origin of 36 cardiac glycosides being found in over 40 species contained within 36 genera and 11 families. The Ebers Papyrus of 1500 BC tells of the diuretic effect of the Mediterranean squill, Drimia maritima, a member of the lily family. The purple foxglove was named Digitalis from the shape of the flowers (digitus, a finger). But why "foxglove"? This is an older name and not the only one, others being fairy fingers and fairy gloves. It is said that the fairies gave the flowers to foxes to wear on their feet so that they could move in magic silence up to hens or away from men. Dr William Withering made the first scientific study of the foxglove in 1775 demonstrating its value in dropsy (oedema) but it was much later, in 1905, that Dr James Mackenzie showed that its special value was in heart failure with atrial fibrillation.

In 1930 Dr Sydney Smith isolated a new glycoside, which he called digoxin, from the Balkan or woolly foxglove Digitalis lanata. Digoxin is extracted directly from the plant, and is not synthesised. Strophanthin is present in species of the African genus Strophanthus. It belongs to the family Apocynaceae, which also contains the plants that yield the Vinca alkaloids and reserpine. It was discovered from its use as an arrow poison, not from folk medicine.
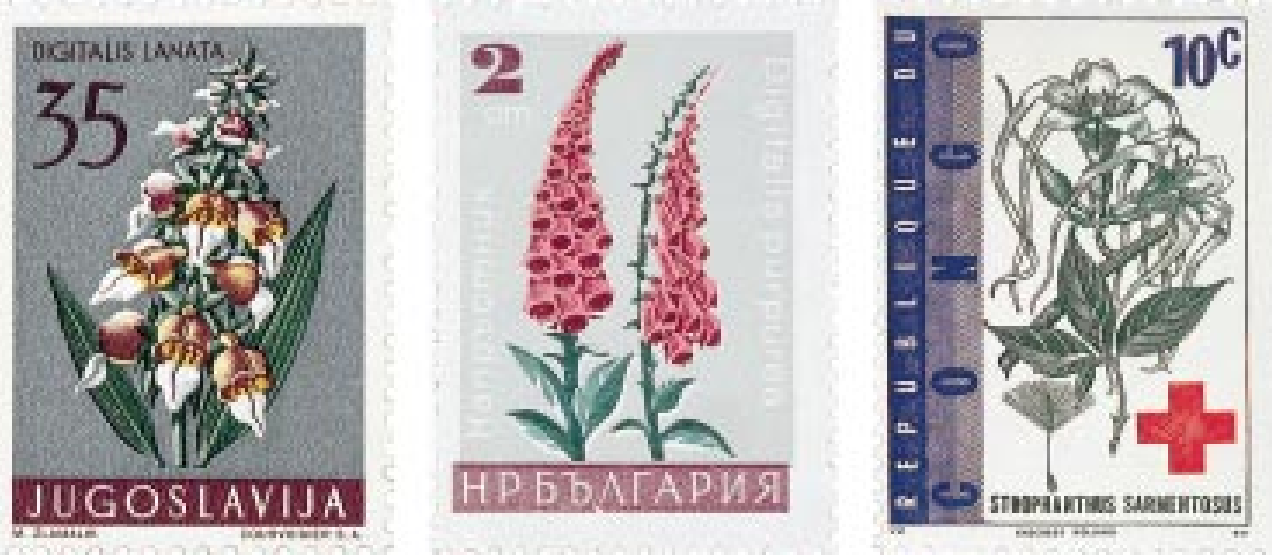